\title{
Is propofol an optimal agent for procedural sedation and rapid sequence intubation in the emergency department?
}

\author{
Kerry Wilbur, BSc (Pharm), Pharm D; *† Peter J. Zed, BSc, BSc (Pharm), Pharm D $\dagger+$
}

See related Commentary, page 311.

\begin{abstract}
Objective: We conducted a qualitative systematic review to evaluate the efficacy and safety of propofol for direct current cardioversion (DCC), rapid sequence intubation (RSI) and procedural sedation in adult emergency department (ED) patients.

Data source: MEDLINE (1966 to September 2000), PubMed (to September 2000), EMBASE (1988 to September 2000), Database of Systematic Reviews (to September 2000), Best Evidence (1991 to September 2000) and Current Contents (1996 to September 2000) databases.

Study selection: English-language, randomized, comparative evaluations of propofol for procedures routinely conducted in adults ( $>18$ years) were included. Direct current cardioversion, RSI and procedural sedation were considered.

Data extraction: Efficacy and safety endpoints were evaluated for all trials. For DCC and procedural sedation trials, efficacy measures included induction and recovery times, as well as the association for successful procedure. For the RSI trials, optimal intubating conditions were evaluated as the primary efficacy endpoint. Safety measures included hemodynamic changes, apnea rates and adverse effects.

Data synthesis: In the setting of DCC, efficacy and safety outcomes were similar for propofol, thiopental, etomidate and methohexital. All of these agents provided markedly shorter induction and recovery times than midazolam. Patients who were pre-medicated with fentanyl exhibited prolonged recovery times and greater decreases in blood pressure. When used for RSI, propofol administration was associated with satisfactory intubating conditions that were comparable to those seen with thiopental and etomidate. Blood pressure reductions were seen in both DCC and RSI studies. Apneic episodes (>30 seconds) occurred in $23 \%$ of propofol recipients, $28 \%$ of thiopental recipients and $7 \%$ of etomidate and midazolam recipients. Apart from the DCC studies described, no procedural sedation studies met our predefined review eligibility criteria.

Conclusion: The body of literature evaluating propofol for DCC and RSI in the ED is limited. There is evidence to support the use of propofol for DCC and RSI, but this evidence comes from stable patients in non-ED settings. Further ED-based randomized comparative trials should be conducted before propofol is adopted for widespread use in the ED.
\end{abstract}

RÉSUMÉ

Objectif : Nous avons mené une revue qualitative méthodique afin d'évaluer l'efficacité et l'innocuité du propofol pour la cardioversion, l'intubation à séquence rapide (ISR) et la sédation

\footnotetext{
*Pharmacotherapeutic Specialist, Internal Medicine, Vancouver Hospital and Health Sciences Centre, Vancouver, BC, and tClinical Assistant Professor, Faculty of Pharmaceutical Sciences, University of British Columbia, Vancouver, BC; $¥$ Pharmacotherapeutic Specialist, Emergency Medicine, Vancouver Hospital and Health Sciences Centre
}

Received: Jan. 18, 2001; final submission: July 24, 2001; accepted: July 27, 2001

This article has been peer reviewed. 
procédurale chez les patients adultes reçus à l'urgence.

Source des données: Les banques de données de MEDLINE (1966 à septembre 2000), PubMed (jusqu'à septembre 2000), EMBASE (1988 à septembre 2000), Database of Systematic Reviews (jusqu'à septembre 2000), Best Evidence (1991-septembre 2000) et Current Contents (1996-septembre 2000).

Choix d'étude : Des évaluations en langue anglaise randomisées, comparatives du propofol pour les interventions routinières chez des adultes ( $>18$ ans) furent incluses. La cardioversion, I'ISR et la sédation procédurale furent étudiées.

Collecte des données : Les paramètres d'efficacité et d'innocuité furent évalués pour tous les essais. Pour les essais de cardioversion et de sédation procédurale, les paramètres d'efficacité comprenaient les délais d'induction et de récupération, ainsi que l'association pour une intervention réussie. Pour les essais de I'IRS, les conditions optimales d'intubation furent évaluées comme le principal paramètre d'efficacité. Les paramètres d'innocuité comprenaient les changements hémodynamiques, les taux d'apnée et les effets indésirables.

Synthèse des données: Dans le cadre de la cardioversion, les résultats de l'efficacité et de l'innocuité furent similaires pour le propofol, le thiopental, l'étomidate et le méthohexital. Tous ces agents procurèrent des temps d'induction et de récupération significativement plus courts que le midazolam. Les patients ayant reçu une pré-médication au fentanyl présentaient des temps de récupération prolongés et un abaissement plus marqué de la tension artérielle. Administré lors de I'ISR, le profolol était associé à des conditions d'intubation satisfaisantes qui étaient comparables aux conditions observées avec le thiopental et l'étomidate. Des diminutions de la tension artérielle furent observées tant dans le cadre des études de la cardioversion que de I'ISR. Des épisodes d'apnée (>30 secondes) se produisirent chez $23 \%$ des patients traités au propofol, $28 \%$ des patients traitées au thiopental, et $7 \%$ des patients traités à l'étomidate et au midazolam. Mis à part les études de cardioversion décrites, aucune étude de sédation procédurale ne répondait à nos critères d'admission prédéfinis.

Conclusion : La littérature évaluant le rendement du propofol pour la cardioversion et I'ISR à l'urgence est limitée. Des preuves existent appuyant le recours au propofol pour la cardioversion et I'ISR, mais celles-ci ont été observées chez de patients stables dans des conditions non urgentes. On devrait procéder à d'autres essais randomisés à l'urgence avant d'adopter le propofol pour usage répandu au département d'urgence.

Key words: propofol, rapid sequence intubation, conscious sedation, procedural sedation, cardioversion, thiopental, etomidate, midazolam

\section{Introduction}

Many brief, painful, non-elective procedures are performed in the emergency department (ED), including direct current cardioversion (DCC), reduction of fractures and dislocations, abscess incision and drainage and rapid sequence intubation (RSI). It is inhumane to perform these procedures without adequate sedation and analgesia., ${ }^{1,2}$ In the case of procedural sedation, amnesia, anxiolysis and analgesia are important, while, during RSI, deep sedation is critical to augment neuromuscular blockade and create optimal intubating conditions. ${ }^{1,3}$

The ideal agent for ED sedation should have rapid onset, sufficient duration of action for the procedure, and short recovery time with minimal adverse effects. ${ }^{4}$ There is no ideal agent, but several are considered suitable for ED use. In recent years, midazolam, fentanyl and ketamine (or combinations of these agents) have been the standard of care for ED procedural sedation. ${ }^{5-11}$ When titrated properly, they provide sufficient sedation and analgesia to facilitate brief painful procedures. ${ }^{71}$ Unfortunately, opioid-benzodiazepine combinations can be associated with respiratory depression, airway compromise or, more commonly, prolonged sedation leading to protracted ED length of stay. For ED rapid sequence intubation various induction agents are used, including midazolam, ketamine, thiopental and, most recently, etomidate. ${ }^{3,12-15}$

Propofol (2,6-diisopropylphenol), a sedative-hypnotic used in the induction and maintenance of anesthesia, is increasingly popular for ED procedural sedation. Propofol infusions are used to sedate ventilated patients in the intensive care unit, and propofol has been extensively investigated for a variety of uses in ambulatory patients, including surgical and diagnostic procedures, and procedural 
sedation during regional anesthesia. ${ }^{16,17}$ Its rapid onset, brief duration, amnesic properties and smooth recovery make it an appealing agent for use in the ED; however, like other agents in common use, propofol may cause hypotension, respiratory depression and apnea. ${ }^{17}$

The objective of this paper was to systematically review published evidence describing the efficacy and safety of propofol for direct current cardioversion, rapid sequence intubation and ED procedural sedation in adult patients.

\section{Methods}

\section{Data source}

We conducted a systematic search of MEDLINE (1966 to September 2000), PubMed (to September 2000), EMBASE (1988-September 2000), Database of Systematic Reviews (to September 2000), Best Evidence (1991-September 2000) and Current Contents (1996-September 2000) databases, looking for English language full reports. Search terms included: propofol, cardioversion, cardiac electroversion, electric defibrillation, electric countershock, rapid sequence intubation, procedural intubation, respiratory tract intubation, endotracheal intubation, laryngoscopy, intratracheal anesthesia, conscious sedation, and procedural sedation. Additional papers were located by hand-searching reference lists in retrieved articles.

\section{Study selection}

Prospective, randomized, comparative evaluations of propofol for DCC, RSI and procedural sedation of adults ( $>18$ years) were eligible for inclusion. Articles were excluded if they were: studies of propofol in patients undergoing surgery; neurological or gastrointestinal investigations; evaluations of propofol for laryngeal mask airway insertion; comparisons between propofol and volatile anesthetic agents; studies in which propofol was administered in all intervention arms. To determine eligibility, both authors independently evaluated the titles and abstracts from all identified citations. If eligibility remained uncertain, full text was reviewed.

\section{Data extraction}

The authors independently evaluated efficacy and safety endpoints for all trials. For DCC and procedural sedation trials, efficacy measures included induction and recovery times, and procedural success, as defined in the source article. For RSI trials, the primary efficacy endpoint was optimal intubating conditions, as defined in the source article.

\section{Results}

\section{Direct current cardioversion}

The search strategy identified 12 reports of propofol use for DCC. Three were excluded because they were foreign language, 1 because it was a case report and 1 because it did not compare propofol to another intervention arm. Six studies with a total of 218 patients met the defined eligibility criteria and were included for review (Table 1), ${ }^{18-23}$ although only 2 of these studies were blinded. ${ }^{19,23}$

\section{Drug administration}

All 6 studies evaluated propofol in patients undergoing elective cardioversion but none specifically addressed ED cardioversion. In 4 studies, ${ }^{18-21}$ propofol was administered as an intravenous (IV) bolus, whereas in the remaining $2^{22,23}$ it was given by continuous infusion. Thiopental was the comparator in 4 studies, ${ }^{18-21}$ midazolam in $3,{ }^{19,20,23}$ etomidate in $2,{ }^{20,22}$ and methohexital in $1 .{ }^{23}$ Mean total propofol dose ranged from 1.4 to $2.7 \mathrm{mg} / \mathrm{kg}$. Nearly all patients received supplemental oxygen prior to and during their procedure.

\section{Induction and recovery}

Times to induction were similar with propofol, thiopental, methohexital and etomidate, but significantly longer with midazolam. Recovery times were also similar for propofol and thiopental; however, in one study, time to awakening with propofol was 3 minutes longer than with thiopental ( $p$ $<0.002) .{ }^{21}$ Conversely, propofol was associated with statistically shorter recovery time as measured by Maddox Wing and visual analogue scale (VAS) when compared with thiopental, despite no difference in time to opening eyes to command. ${ }^{18}$ Midazolam consistently demonstrated prolonged confusion and time to orientation, with some patients still asleep as long as 4 hours after cardioversion. ${ }^{19}$

\section{Procedural success}

Cardioversion success rates were similar for all agents. One study reported a trend toward increased energy requirements to convert propofol (versus thiopental) recipients, ${ }^{18}$ but this was not seen in other studies.

\section{Hemodynamic effects}

In almost half of the studies, propofol induction was associated with statistically significant reductions in mean arterial pressure (MAP) and systolic blood pressure (SBP), whether administered by bolus or infusion; however, these hemodynamic changes were not significantly different from those seen with midazolam. In 2 of 4 studies comparing propofol and thiopental, propofol demonstrated signifi- 


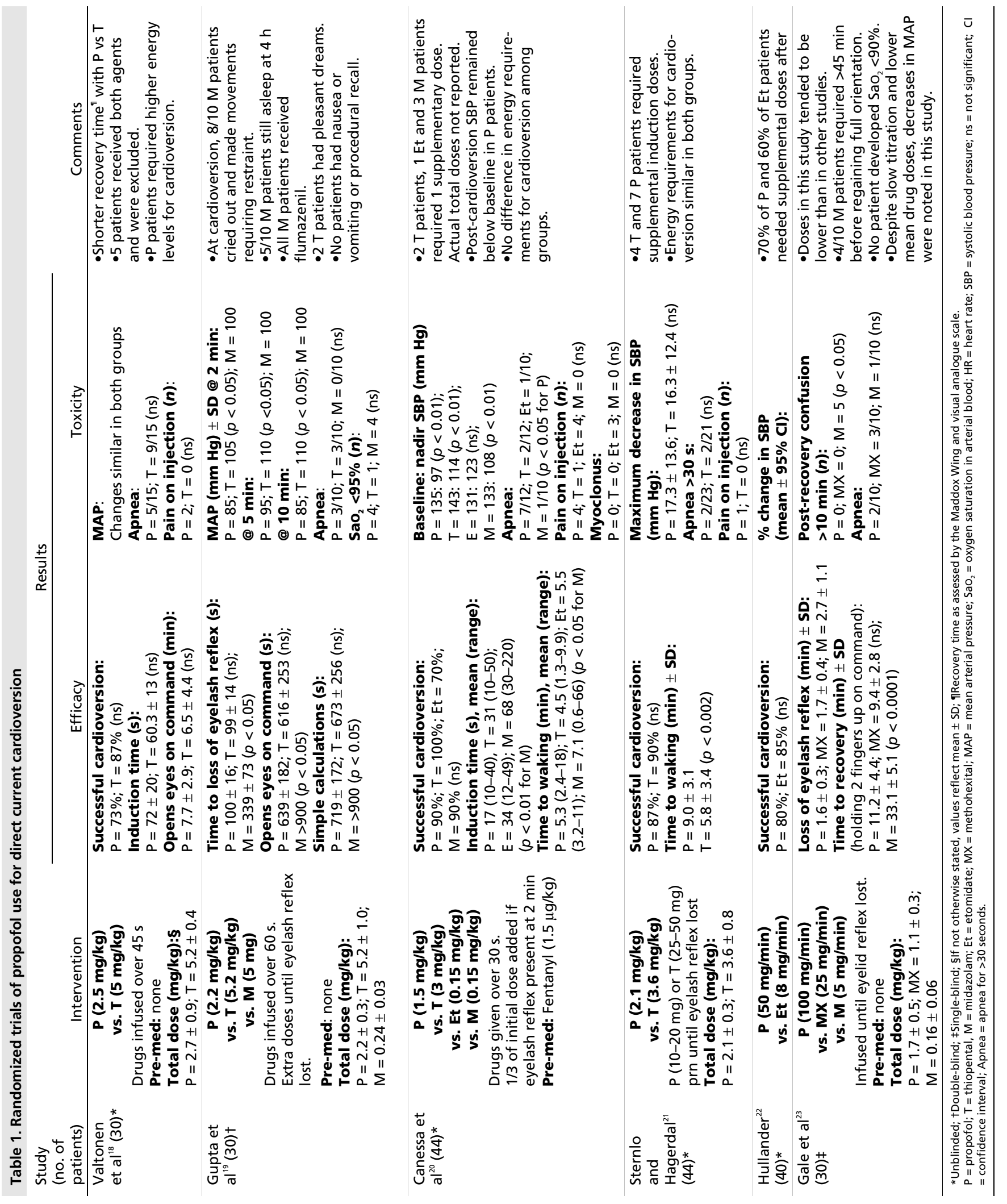


cantly greater decreases in blood pressure, although one of these was confounded by the use of fentanyl pre-medication. ${ }^{19,20}$ No patients in any study had hemodynamic changes that interfered with cardioversion or recovery.

\section{Adverse events}

Apneic episodes ( $>30 \mathrm{~s}$ ) were reported in $10 \%-60 \%$ of propofol recipients and in a similar proportion of thiopental recipients. ${ }^{20-23}$ Excitatory side effects, including muscular tension and involuntary movements, were generally not reported. Myoclonus was observed more often in etomidate treated patients, but this was statistically significant in only one study. ${ }^{22}$

\section{Rapid sequence intubation}

The search strategy identified over 200 articles studying propofol use for RSI, but only 58 were randomized controlled trials. Twenty-two of these assessed propofol use during surgery, 17 involved children or laryngeal mask airway placement, 13 compared propofol with a volatile anesthetic agent, and 6 included propofol in all treatment arms. Consequently, 7 studies assessing propofol use for RSI in 564 patients met the review eligibility criteria. Of these, 4 were double-blinded, 1 was unblinded and 2 did not describe investigator blinding. ${ }^{24-30}$ The eligible studies are summarized in Table 2.

\section{Drug combinations}

Propofol was compared to thiopental in 6 studies $^{24,26-30}$ and etomidate in $2 .{ }^{25,26} \mathrm{In}$ all studies, patients underwent RSI prior to elective surgery, and in all studies, 2.0 or 2.5 $\mathrm{mg} / \mathrm{kg}$ of propofol was administered as a short infusion over 15 to 60 seconds. Table 2 shows that propofol was the lone induction agent in 4 studies $^{24-26,29}$ and was co-administered with alfentanil in 3 studies. ${ }^{27,28,30}$ Pre-medications were used in 4 studies, including oral diazepam, ${ }^{29}$ fentany ${ }^{24,26}$ and glycopyrrolate. ${ }^{30}$ Neuromuscular blocking agents were administered in 5 studies, including rocuronium, ${ }^{24,25,28}$ vecuronium ${ }^{29}$ and succinylcholine. ${ }^{26}$

\section{Intubating conditions}

Table 2 shows that, in patients receiving rocuronium, propofol provided better intubation conditions than thiopental ${ }^{24}$ or etomidate. ${ }^{25}$ In one of these studies ${ }^{24}$ propofol was associated with a higher rate of successful intubation at 70 seconds and a shorter mean time to intubation than thiopental. Two studies showed that propofol-alfentanil provided similar intubating conditions to thiopental-succinylcholine, ${ }^{29,30}$ even when vecuronium was administered to the propofol group. ${ }^{30}$ Sparr and colleagues found that thiopental-rocuronium provided similar intubating conditions to propofol-rocuronium, but that neither combination was as effective as thiopental-succinylcholine unless alfentenil was added. ${ }^{28}$

\section{Adverse effects}

In 3 studies, propofol caused greater blood pressure reductions than etomidate or thiopental; ${ }^{25-27}$ however, no patients in any study required circulatory support because of hypotension. Most studies documented a rise in heart rate with intubation, which was greater in thiopental than propofol groups, ${ }^{27,29,30}$ although the differences seen were unlikely to be clinically important. One patient treated with propofol-alfentanil developed transient bradycardia of 30 beats/min. Two studies suggested that heart rate changes were similar for propofol- and etomidate-treated patients. ${ }^{25,26}$ One study documented significant QT interval prolongation with thiopental relative to propofol and, in this study, 1 patient developed ventricular tachycardia. ${ }^{29}$

Sparr and colleagues ${ }^{28}$ noted limb movements in $8 \%$ of patients receiving thiopental-succinylcholine vs. $40 \%$ receiving thiopental-rocuronium and $56 \%$ receiving propofol-rocuronium. In another study, limb movement occurred in $18 \%$ of thiopental-succinylcholine recipients vs. $10 \%$ of propofol-alfentanil recipients, but this was not statistically significant. ${ }^{27}$ Coughing occurred in $35 \%-80 \%$ of propofol patients, but this did not differ significantly from other treatment groups. ${ }^{27,30}$ One study documented lower post-intubation airway resistance with propofol compared with etomidate or thiopental, but found no difference in clinically apparent wheezing. ${ }^{26}$

\section{Procedural sedation}

Of 143 articles identified, 49 were randomized controlled trials, but all employed propofol for bronchoscopy, gastrointestinal procedures, orthopedic, abdominal or urological surgery, dental procedures or patient-controlled sedation. Consequently, none met the pre-defined eligibility criteria for this review.

\section{Discussion}

Procedural sedation is a necessary skill for clinicians practising in the ED. ${ }^{1}$ The goals of ED procedural sedation are to protect the patient's safety and welfare; to provide analgesia, anxiolysis, sedation and amnesia during the procedure; to minimize adverse psychological response associated with painful and frightening medical procedures; to control motor behaviour that inhibits the provision of care; and to return patients to a state in which safe discharge is possible. ${ }^{1} \mathrm{Be}-$ 


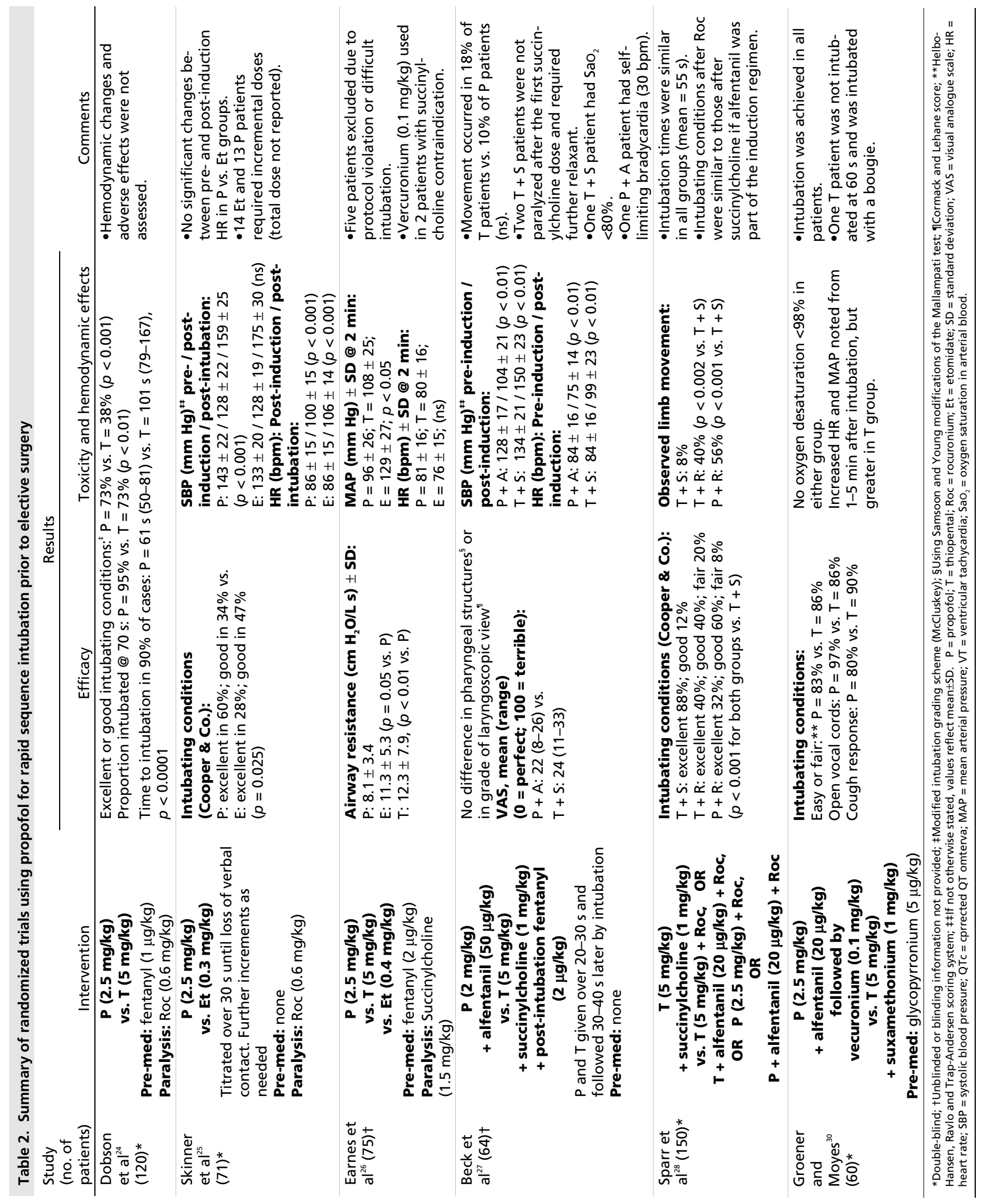


cause of its rapid onset, brief duration and amnesic effects, propofol is an appealing agent, especially for rapid sequence intubation and DCC. Despite this, there are few high quality studies related to these applications. Of those we identified, none were specifically based in the ED and all enrolled stable rather than emergent patients. In addition, only 2 DCC and 4 RSI trials were adequately blinded. This is critical, given that many study endpoints are subjective (e.g., time to orientation, intubation conditions).

\section{Efficacy for DCC and RSI}

Table 1 summarizes the eligible DCC studies and shows that cardioversion success rates were similar regardless of the sedating agent used. Induction times, most often defined as time to loss of eyelash response, ranged from 17 seconds to 2.2 minutes and were similar for propofol, thiopental, etomidate and methohexital. ${ }^{18-23}$ Recovery times (to waking or eye opening) were also similar for propofol, thiopental, etomidate and methohexital, ranging from 4.5 to 11.2 minutes. ${ }^{18-23}$ Thiopental consistently provided the shortest recovery times. ${ }^{18-21}$ Induction and recovery times were approximately 3 times longer with midazolam than with the other agents, and these differences were both statistically and clinically significant.

Procedural recall was reported as an outcome in only 2 studies. In these studies, involving propofol, thiopental, etomidate and midazolam, no patients had procedural recall; ${ }^{19,22}$ although in one, $8 / 10$ midazolam patients cried out and required restraint at the time of cardioversion.

With respect to RSI, 3 studies suggested that intubating conditions were similar with propofol and thiopental, ${ }^{27,28,30}$ 1 suggested propofol was superior to thiopental ${ }^{24}$ and 1 suggested propofol was superior to etomidate. ${ }^{25}$ Unfortunately, these studies employed different pre-medications and paralytic agents, and looked at heterogeneous endpoints; therefore, it is difficult to attribute differences in intubating conditions to the induction agents alone.

\section{Adverse effects}

Propofol is a cardiovascular depressant that causes doserelated blood pressure reductions. After propofol induction, systolic blood pressure drops below $90 \mathrm{~mm} \mathrm{Hg}$ in approximately $12 \%$ of patients, and more severe hypotension has been associated with older age, female gender, abdominal surgery, poor physical status and concomitant use of opioids or benzodiazepines. ${ }^{31}$ Other authors have shown that fluid pre-loading, pre-induction ephedrine sulphate and reduced infusion rates minimize propofol-induced hypotension. ${ }^{32-36}$ In the studies reviewed, propofol's hypotensive effects were significant and were not overcome by the hypertensive responses related to cardioversion and intubation. In most cases, propofol caused more marked hypotension than thiopental ${ }^{19,20,26,27}$ or etomidate. ${ }^{22,25,26}$

Like other induction agents, propofol may cause reduced tidal volume and apnea. ${ }^{17,37,38}$ In the 6 DCC studies reviewed, 21 (23.3\%) of 90 patients who received propofol experienced apnea episodes longer than 30 seconds. ${ }^{18-23}$ This compares to 16 of 58 thiopental recipients (27.5\%), 2 of 30 midazolam recipients $(6.7 \%)$ and 2 of 30 etomidate recipients $(6.7 \%)$.

Movement, tremor, twitching and hiccup have been observed during propofol induction, ${ }^{39}$ but these were not reported in any of the eligible studies reviewed. In contrast, $30 \%-45 \%$ of etomidate recipients suffered episodes of myoclonus. ${ }^{20,22}$

The most common adverse effect reported following propofol use is probably pain on injection, which occurred in $0 \%-33 \%$ of patients in this review. ${ }^{22,20}$ Lidocaine premedication within a few minutes of propofol administration and injecting into the forearm or anticubital fossa, as opposed to the dorsum of the hand, have both been shown to reduce pain..$^{40,41}$

\section{Should propofol be used for ED procedural sedation}

Relatively few Canadian EDs use propofol for procedural sedation, and those that do have not published their experience. There are few reports of propofol use for ED procedural sedation, and none that met our pre-defined inclusion criteria.

Totten and Zambito described 2 cases of successful temperomandibular joint relocation. ${ }^{42}$ Swanson and colleagues used a propofol-fentanyl combination successfully in 4 patients. ${ }^{43}$ Later they studied a larger series of 20 adults, ${ }^{44}$ using fentanyl pre-medication ( $2 \mu \mathrm{g} / \mathrm{kg}$ over $2 \mathrm{~min}$ ) followed by propofol infusion $(0.21 \mathrm{mg} / \mathrm{kg} / \mathrm{min}$ until speech slurred, then $3-6 \mathrm{mg} / \mathrm{kg} / \mathrm{h}$ until procedure completion). With this regimen, they reported onset of sedation at $6.6 \pm 3.2 \mathrm{~min}$ utes, a mean recovery interval of $6.1 \pm 4.1$ minutes, and a mean administered dose of $200 \pm 160 \mathrm{mg}$. Median patient satisfaction score was $97 \mathrm{~mm}$ on a 100-mm VAS and 6 patients suffered adverse effects, including pain on injection $(n=3)$, apnea $<30$ seconds $(n=2)$ and hypotension $(n=1)$.

Like other agents now used for ED procedural sedation, propofol was initially restricted to use by anesthetists, and its gradual move into the ED has generated considerable controversy. ${ }^{45,46}$ Proponents suggest that, with careful titration and monitoring, trained emergency physicians can provide safe and effective procedural sedation using propofol. ${ }^{43,44}$ Others feel that the evidence does not yet support its use in this setting. ${ }^{46}$ 
The pivotal distinction between propofol and midazolam (the time-honoured ED agent) is propofol's higher risk of oversedation and loss of airway reflexes. Using midazolam, it is consistently possible to avoid oversedation; however, with propofol, this goal is more difficult to achieve, and periods of deep sedation, apnea and loss of airway reflexes will occur in some patients. Further, because neither propofol nor midazolam possess analgesic properties, it is often necessary to co-administer an opioid during painful procedures, which further increases the likelihood of hemodynamic compromise or respiratory depression. ${ }^{47}$ The evidence reviewed suggests that, if propofol is used in the $\mathrm{ED}$, controlled infusion may be the preferred method of administration to minimize the risk of apnea and hemodynamic compromise.

This systematic review shows that there is evidence to support the use of propofol for common ED procedures like RSI and DCC. Ironically, the trials supporting these applications were conducted outside the ED and enrolled stable patients requiring airway management for elective surgery. Consequently, there are no data to support propofol use for RSI following trauma or in the hemodynamically compromised patients more often seen in the ED. There is perhaps more justification to use propofol for ED procedural sedation than for RSI. Newer induction agents like etomidate, which lacks propofol's adverse hemodynamic effects, appear to be more attractive for ED RSI. ${ }^{13-15}$ Unfortunately, etomidate is not yet available in Canada.

\section{Conclusion}

Before propofol use becomes widespread for ED procedural sedation, further randomized trials comparing propofol to more common ED regimens like midazolam-fentanyl or ketamine should be conducted. When the necessary safety and efficacy data are gathered, emergency physicians can feel more comfortable about adding this potentially valuable agent to their armamentarium in a safe, evidence-based manner.

Competing interests: None declared.

Acknowledgements: We thank Dr. Riyad Abu-Laban and Dr. David Harrison, Department of Emergency Medicine, Vancouver Hospital and Health Sciences Centre, Vancouver, BC, for their review and editorial contribution during the preparation of this manuscript.

\section{References}

1. Innes G, Murphy M, Nijssen-Jorden C, Ducharme J, Drummond A. Procedural sedation and analgesia in the emergency department.
Canadian consensus guidelines. J Emerg Med 1999;17:145-56.

2. American College of Emergency Physicians. The use of pediatric sedation and analgesia [policy statement]. Ann Emerg Med 1993;22:626-7.

3. Gerardi MJ, Sacchetti AD, Cantor RM, Santamaria JP, Gausche M, Lucid W, et al. Rapid-sequence intubation of the pediatric patient. Ann Emerg Med 1996;28:55-74.

4. Schneider MS, Coates WC. Use of ultrashort-acting hypnotic agents in emergency departments. West J Med 1996;164:64-5.

5. Grafstein E, Innes G, Roland K. Do injection drug users have different medication requirements in procedural sedation? [abstract]. CJEM 2000;2(3):180.

6. Innes G, Grafstein E, Christenson JM, Roland K. Ketamine vs. fentanyl/midazolam for procedural sedation in intravenous drug users [abstract]. CJEM 2000;2(3):185.

7. Wright SW, Chudnofsky CR, Dronen SC, Wright MB, Borrow SW. Midazolam use in the ED. Am J Emerg Med 1990;8:97-100.

8. Ramoska EA, Linkenheimer R, Glascow C. Midazolam use in the ED. J Emerg Med 1991;9:247-51.

9. Chudnofsky CR, Wright SW, Dronen SC, Borron SW, Wright MB. The safety of fentanyl use in the ED. Ann Emerg Med 1989;18:635-9.

10. Epstein FB. Ketamine dissociative sedation in pediatric emergency medical practice. Am J Emerg Med 1993;11:180-2.

11. Chudnofsky CR, Weber JE, Stoyanoff PJ, Colone PD, Wilkerson MD, Hallinen DL, et al. A combination of midazolam and ketamine for procedural sedation and analgesia in adult emergency department patients. Acad Emerg Med 2000;7:228-35.

12. Sivilotti MLA, Ducharme J. Randomized, double-blind study on sedatives and hemodynamics during rapid-sequence intubation in the emergency department: The SHRED Study. Ann Emerg Med 1998;31:313-24.

13. Sokolove PE, Price DD, Okada P. The safety of etomidate for emergency rapid sequence intubation of pediatric patients. Pediatr Emerg Care 2000;16:18-21.

14. Smith DC, Bergen JM, Smithline H, Kirschner R. A trial of etomidate for rapid sequence intubation in the emergency department. J Emerg Med 2000;18:13-6.

15. Bergen JM, Smith DC. A review of etomidate for rapid sequence intubation in the emergency department. J Emerg Med 1997;15:221-30.

16. Mirenda J, Broyles G. Propofol as used for sedation in the ICU. Chest 1995;108:539-48.

17. Bryson HM, Fulton BR, Faulds D. Propofol: an update of its use in anaesthesia and conscious sedation. Drugs 1995;50:513-59.

18. Valtonen M, Kanto J, Klossner J. Anaesthesia for cardioversion: a comparison of propofol and thiopentone. Can J Anaesth 1988; 35:479-83. 
19. Gupta A, Lennmarken C, Vegfors M, Tayden H. Anesthesia for cardioversion. A comparison between propofol, thiopenton, and midazolam. Anaesthesia 1990;45:872-5.

20. Canessa R, Guillermo L, Urzua J, Dagnino J, Concha M. Anesthesia for elective cardioversion: a comparison of four anesthetic agents. J Cardiothor Vasc Anesth 1991;5:566-8.

21. Sternlo JE, Hagerdal M. Anaesthesia for cardioversion - clinical experience with propofol and thiopentone. Acta Anaesthesiol Scan 1991;35:609-15.

22. Hullander RM, Leivers D, Wingler K. A comparison of propofol and etomidate for cardioversion. Anesth Analg 1993;77:690-4.

23. Gale DW, Usaf M, Grissom TE, Mirenda JV. Titration of intravenous anesthetics for cardioversion: a comparison of propofol, methohexital, and midazolam. Crit Care Med 1993;21:1509-13.

24. Dobson AP, McCluskey A, Meakin G, Baker RD. Effective time to satisfactory intubation conditions after administration of rocuronium in adults. Comparison of propofol and thiopentone for rapid sequence induction of anaesthesia. Anaesthesia 1999; 54:172-97.

25. Skinner HJ, Biswas A, Mahajan RP. Evaluation of intubating conditions with rocuronium and either propofol or etomidate for rapid sequence induction. Anaesthesia 1998;53:702-10.

26. Earnes WO, Rooke A, Sai-Chuen R, Bishop MJ. Comparison of the effects of etomidate, propofol, and thiopental on respiratory resistance after tracheal intubation. Anesthesiology 1995;83: 1307-11.

27. Beck GN, Masterson GR, Richards J, Bunting P. Comparison of intubation following propofol and alfentanil with intubation following thiopentone and suxamethonium. Anaesthesia 1993; 48:876-80.

28. Sparr HJ, Giesinger S, Ulmer M, Hollenstein-Zacke M, Luger TJ. Influence of induction technique on intubating conditions after rocuronium in adults: comparison with rapid-sequence induction using thiopentone and suxamethonium. Br J Anaesth 1996;77:339-42.

29. Lindgren L, Yli-Hankala A, Randell T, Kirvela M, Scheinin M, Neuvonen PJ. Haemodynamic and catecholamine responses to induction of anaesthesia and tracheal intubation: comparison between propofol and thiopentone. Br J Anaesth 1993;70:306-10.

30. Groener R, Moyes DG. Rapid tracheal intubation with propofol, alfentanil and a standard dose of vecuronium. Br J Anaesth 1997;79:384-5.

31. Hug CC Jr, McLeskey CH, Nahrwold ML, Roizen MF, Stanley TH, Thisted RA, et al. Hemodynamic effects of propofol: data from over 25,000 patients. Anesth Analg 1993;77(Suppl):S21-9.

32. El-Beheiry H, Kim J, Milne B, Deegobin R. Prophylaxis against the systemic hypotension induced by propofol during rapid-sequence intubation. Can J Anaesth 1995;42:875-8.
33. Peacock JE, Lewis RP, Reilly CS, Nimmo WS. Effect of different rates of infusion of propofol for induction of anesthesia in elderly patients. Br J Anaesth 1990;65:346-52.

34. Rolly G, Versichelen L, Huyghe L, Mungroop H. Effect of speed of injection on induction of anaesthesia using propofol. $\mathrm{Br}$ J Anaesth 1985;57:743-6.

35. Gillies GWA, Lees NW. The effects of speed of injection on induction with propofol. Anaesthesia 1989;44:386-8.

36. Dundee JW, Robinson FP, McCollum JSC, Patterson CC. Sensitivity to propofol in the elderly. Anaesthesia 1986;41:482-5.

37. McCollum JS, Dundee JW. Comparison of induction characteristics of four intravenous anesthetic agents. Anaesthesia 1986;41:995-1000.

38. Blouin RT, Conrad PF, Gross JB. Time course of ventilatory depression following induction doses of propofol and thiopental. Anesthesiology 1991;75:940-4.

39. American Society of Anesthesiologists. Practice guidelines for sedation and analgesia by non-anesthesiologists. Anesthesiology 1996;84:459-71.

40. Picard P, Tramer MR. Prevention of pain on injection with propofol: a quantitative systematic revew. Anesth Analg 2000; 90:963-9.

41. Johnson RA, Harper NJ, Chadwick S, Vohra A. Pain on injection of propofol. Methods of alleviation. Anaesthesia 1990;45: 439-42.

42. Totten VY, Zambito RF. Propofol bolus facilitates reduction of luxed temporomandibular joints. J Emerg Med 1998;16:467-70.

43. Swanson ER, Seaberg DC, Stypula RW, Troianos CA. Propofol for conscious sedation: a case series. Acad Emerg Med 1995; 2:661-3.

44. Swanson ER, Seaberg DC, Mathias S. The use of propofol for sedation in the emergency department. Acad Emerg Med 1996; 3:234-8.

45. Innes G. Emergency department sedation guidelines: a tale of two specialties [editorial]. CJEM 1999;1(2):88.

46. Green SM. Propofol for emergency department procedural sedation - not yet ready for prime time. Acad Emerg Med 1999; 6:975-8.

47. Bailey PL, Pace NL, Ashburn MA, Moll JW, East KA, Stanley TH. Frequent hypoxemia and apnea after sedation with midazolam and fentanyl. Anesthesiology 1990;73:826-30.

Correspondence to: Dr. Peter J. Zed, CSU Pharmaceutical Sciences, Vancouver Hospital and Health Sciences Centre, 855 West 12th Ave., Vancouver BC V5Z 1M9; 604 875-4077, fax 604 875-5267, zed@inter change.ubc.ca 